\title{
Maternal obstetric and socio-demographic determinants of low birth weight: a retrospective cross-sectional study in Ghana
}

Shamsudeen Mohammed ${ }^{1 *}$ (D) Irene Bonsing ${ }^{2}$, Ibrahim Yakubu ${ }^{3}$ and Winifred Porsaa Wondong ${ }^{3}$

\begin{abstract}
Background: Birth weight is an important predictor of early neonatal mortality, morbidity, and long-term health outcomes. Annually, approximately 20 million babies are born globally with weights less than $2.5 \mathrm{~kg}$. In sub-Saharan Africa, the prevalence of LBW is around 13 to 15 percent. In Ghana, 10\% of babies born in 2014 were with LBW. The aim of this study was to identify maternal socio-demographic and obstetric risk factors associated with the birth weight of newborns in the Sunyani Municipality of Ghana.

Methods: This retrospective cross-sectional study analysed data from 931 birth records of all deliveries between January 1 and December 31, 2017, at the Sunyani Municipal Hospital in the Brong-Ahafo Region of Ghana. Univariate and multivariable logistic regression models were fitted to estimate the effect of maternal factors on low birth weight.

Results: We found that the mean age of the participants and the mean gestational age at birth were 27.21(SD= 5.50) years and $37.95(S D=1.85)$ weeks respectively. Nearly $10 \%$ of the infants born within the study period had birth weights below $2.5 \mathrm{~kg}$. The findings revealed that the odds of delivering LBW baby were significantly high (OR 1.77, 95\%Cl 1.14-2.76) among urban dwellers. However, mothers who attended or completed secondary or higher education were $63 \%(95 \% \mathrm{Cl} 0.20-0.78)$ less likely to give birth to a LBW baby when compared with uneducated mothers. We found that the odds of LBW significantly decreased with every one-week increase in gestational age (OR $0.6795 \% \mathrm{Cl}$ 0.59-0.76) and significantly increased with increasing parity (OR $1.4395 \% \mathrm{Cl}$ 1.21-1.70). Further, the likelihood of delivering LBW baby decreased with every additional ANC visit (OR 0.78 $95 \% \mathrm{Cl}$ 0.67-0.90) and with every additional gram of haemoglobin (OR 0.78 95\% Cl 0.63-0.95).

Conclusion: The evidence from this study suggests that maternal educational level, residence, haemoglobin level, parity, number of ANC visits, and gestational age are independent predictors of low birth weight. The current findings add substantially to the growing literature on the influence of maternal socio-demographic and obstetric factors on LBW in resource-constrained settings and provide empirical data for clinical and public health interventions aimed at reducing low birth weight and its associated complications.
\end{abstract}

Keywords: Birth weight, Obstetric factors, Socio-demographic factors, Low birth weight, Determinants, Ghana

\footnotetext{
* Correspondence: deen0233@gmail.com

'Department of Nursing, College of Nursing and Midwifery, P. O. Box 10

Nalerigu, Ghana

Full list of author information is available at the end of the article
}

(C) The Author(s). 2019 Open Access This article is distributed under the terms of the Creative Commons Attribution 4.0 International License (http://creativecommons.org/licenses/by/4.0/), which permits unrestricted use, distribution, and reproduction in any medium, provided you give appropriate credit to the original author(s) and the source, provide a link to the Creative Commons license, and indicate if changes were made. The Creative Commons Public Domain Dedication waiver (http://creativecommons.org/publicdomain/zero/1.0/) applies to the data made available in this article, unless otherwise stated. 


\section{Plain English summary}

At birth, most term newborns weigh between $2.5 \mathrm{~kg}$ and $4.0 \mathrm{~kg}$. Those with an abnormally low or abnormally high birth weight require special attention and care to prevent neonatal death. According to the World Health Organization, the risk of neonatal death is much higher among neonates with low birth weight (LBW) than those with normal birth weight since LBW babies are more susceptible to birth asphyxia, trauma, hypothermia, hypoglycaemia, respiratory disorders, and infections [1]. Notwithstanding these immediate health consequences, LBW has long-term consequences in the form of growth inhibition, impairment of cognitive development, and increased incidence of chronic diseases such as type 2 diabetes, hypertension and cardiovascular diseases [2]. The 2014 Ghana Demographic and Health Survey reported that of those newborns weighed at birth, $10 \%$ had a LBW. We analysed data from birth records to identify the maternal factors associated with LBW in the Sunyani Municipality of Ghana. We found that maternal educational level, residence, haemoglobin level, parity, number of ANC visits, and gestational age are the sociodemographic and obstetric determinants of LBW in the municipality. The current findings add substantially to our understanding of the determinants of birth weight and provide empirical data for clinical and public health interventions aimed at reducing LBW and associated complications.

\section{Background}

Birth weight is the first weight of a newborn after delivery. It is an important predictor of early neonatal mortality, morbidity, and long-term health outcomes [2]. At birth, most term newborns weigh between $2.5 \mathrm{~kg}$ and $4.0 \mathrm{~kg}$. Those with an abnormally low or abnormally high birth weight require special attention and care to prevent neonatal death [3]. Newborns with a birth weight of less than $2.5 \mathrm{~kg}$ are considered to be of LBW (LBW), irrespective of the gestational age. Annually, approximately 20 million babies are born globally with weights less than $2.5 \mathrm{~kg}$. In sub-Saharan Africa, the prevalence of LBW is around 13 to $15 \%$ [2]. The 2014 Ghana Demographic and Health Survey reported that of those newborns weighed at birth, $10 \%$ had a LBW [4]. Studies have shown that LBW is the result of either a short gestation period (less than 37 completed weeks of gestation) or intrauterine growth restriction. These two major factors of LBW have varied aetiology and risks of mortality and morbidity [5]. In 2010, approximately 32 million babies were born with LBW in low and middleincome countries of which 2.8 million of them were preterm. Furthermore, Of the 18 million LBW babies born each year, approximately 59\% are due to intrauterine growth restriction in term infants and $41 \%$ are attributable to prematurity [5]. Globally, a huge burden of foetal growth restriction exists and babies born at term with low birth weight are linked to intrauterine growth restriction. For instance, in 1998 and in 2010, about 13.7 million and 10.6 million infants were born at term with low birth weight in low and middle-income countries respectively and these LBWs were attributed to intrauterine growth restrictions [5].

Evidence have demonstrated that LBW has significant consequences for the health and survival of neonates and is an underlying factor in neonatal deaths [6]. According to the World Health Organization, the risk of neonatal death is much higher among neonates with LBW than those with normal birth weight since LBW babies are more susceptible to birth asphyxia, trauma, hypothermia, hypoglycaemia, respiratory disorders, and infections [1]. Notwithstanding these immediate health concerns, LBW has long-term consequences in the form of growth inhibition, impairment of cognitive development, and increased incidence of chronic diseases such as type 2 diabetes, hypertension and cardiovascular diseases [2, 7]. Additionally, findings of the 2014 Ghana Demographic and Health Survey suggests that children whose birth weight is less than $2.5 \mathrm{~kg}$ have a higher than average risk of early childhood death [4].

In many low-income countries, LBW is associated with lower socioeconomic status, female sex, increasing parity, young maternal age, low level of maternal education, low caloric intake, malaria, and general morbidity [8-10]. Furthermore, studies have demonstrated a link between $\mathrm{ABO}$ blood groups and birth weight $[11,12]$. For instance, in Turkey, Beyazit et al. reported that pregnant women with type B blood group had significantly lower birth weight babies compared with women with other ABO blood groups [11]. Further, a case control study in Nepal found that maternal blood group AB had some protective effect against delivering a LBW baby [13]. Other potentially important factors in determining newborn weight are maternal haemodynamics, antenatal care visits, folic acid intake, and quality of antenatal care [8-10]. Several studies in low and middle-income countries have shown empirical support for the link that exists between maternal factors and birth weight [14-17]. However, few studies have been conducted on maternal determinants of LBW in the Sunyani Municipality of Ghana. To modify the risk factors of LBW and prevent the life-long complications associated with it, there is the need to understand the determinants of LBW in the municipality. This study was undertaken to identify maternal socio-demographic and obstetric risk factors associated with the LBW of newborns in the Sunyani Municipality of Ghana and to provide empirical data for clinical and public health interventions aimed at preventing $L B W$ and associated complications. 


\section{Methodology}

\section{Study setting and study design}

A retrospective cross-sectional study was conducted in Sunyani Municipal Hospital in the Brong-Ahafo Region of Ghana. The hospital was established in 1927 and upgraded to the status of a municipal hospital in 2004. It is located in the Sunyani Municipal Assembly, one of the 27 districts in the Brong Ahafo Region. The Sunyani Municipal Assembly has a total land area of $506.7 \mathrm{Km}^{2}$. Six hospitals, 12 clinics, seven chips compound, three maternity homes, and three health centres provide health care services to the municipal population of 123 , 224 (61,610 males and 61,614 females) [18].

The Sunyani Municipal Hospital provides $24 \mathrm{~h}$ uninterrupted healthcare services, including specialised services for both insured and uninsured patients from diverse ethnic and socioeconomic backgrounds. It serves as one of the referral centres for the primary level health care facilities in rural and urban communities of the municipality. In 2017, 63,043 outpatients reported at the OPD of the hospital of which 6821 were admitted. Antenatal care attendance in the hospital declined from 10, 813 in 2016 to 9966 in 2017 with a similar decline in the number of women who made four or more visits (1889 in 2016 to 1249 in 2017). Professional nurses and midwives in the maternity unit of the hospital record pregnancy history of mother's, newborn characteristics, delivery information, and socio-demographic characteristics of all mothers in a birth register. We examined birth records of all mothers who delivered live babies in the Sunyani Municipal Hospital between January 1 and December 31, 2017, to determine the influence of maternal socio-demographic and obstetric factors on the birth weight of newborns.

\section{Data extraction and sample size}

Data for the study were extracted from birth registers containing information about maternal and newborn characteristics using a structured data-capturing sheet. The data-capturing sheet was pretested on birth records for March 2018 and appropriate amendments made. Three Registered Nurses (RN) extracted the data from the registers. They were trained on how to extract data from the records and orientated on the eligibility criteria of the study. The second author (IB) supervised the data collectors on daily basis to ensure completeness and consistency of data extraction and allowed frequent scheduled breaks to prevent errors. Permission to use the birth records was granted by the medical superintendent of the hospital. Newborn deliveries recorded in the maternity unit of the hospital between January 1 and December 31, 2017, were 1756. All the newborn deliveries within this period were considered in this study. However, we analysed data from 931 records after excluding records with multiple births, stillbirths, babies with congenital abnormalities, and entries with missing birth weight information. Stillbirths were excluded because the birth weights of the few cases of stillbirths that were recorded within the study period were missing. We excluded records of multiple births and congenital abnormalities because they have a different aetiology and risk profile for LBW [19].

\section{Study variables and categorisation Outcome variable}

The outcome variable in this study was birth weight. Newborn records with birth weight less than $2.5 \mathrm{~kg}$ were considered LBW while those with a birth weight of 2.5 $\mathrm{kg}$ or more were considered as normal birth weight, irrespective of gestational age. Based on these criteria the outcome variable was extracted and coded as a dichotomous variable: 0 "LBW $(<2.5 \mathrm{~kg})$ " and 1 "normal birth weight $(\geq 2.5 \mathrm{~kg})$ ".

\section{Explanatory variables}

Explanatory variables of this study were maternal sociodemographic characteristics and obstetric factors that may influence the birth weight of newborns, given the results of similar previous studies [9, 20-24]. Sociodemographic characteristics that were captured from the records were maternal age in completed years, mother's education level, occupation, and residence. Maternal age at birth was categorised into three groups: <20, 20-30, and $>30$. Education level refers to the highest level of schooling attended by the mother whether completed or not. Education level was classified as uneducated, primary/Junior High School (JHS), and secondary or higher education. Occupation of mothers was classified as employed (government/private), self-employed, unemployed and student. Residence of mothers was coded into two categories: 0 'rural' 1 'urban'.

Maternal factors that were extracted were gravida, parity, number of ANC visits, gestational age, intake of Intermittent Preventive Treatment in pregnancy with sulfadoxine-pyrimethamine (IPTp-SP), haemoglobin level $(\mathrm{Hb})$, and blood group. Gravida was categorised as primigravida, gravida $2-4$ and gravida 5 or more. Parity did not include current birth and was categorised as first-time mothers, $1-3$ previous deliveries, and $\geq 4$ previous deliveries. The total number of antenatal care visits for the pregnancy was classified as $\leq 4$ visits and $>4$ visits. Gestational age was calculated based on the last menstrual period (LMP) or antenatal ultrasound assessment if the LMP was not known. According to WHO, half of babies born at or below 32 weeks in low-income settings die [25]. In this study, gestational age was classified as 26-36 weeks and 37-42 weeks. IPTp-SP was categorised as none (for mothers who did not take a dose of IPT-SP), 1-3 doses, 
and $\geq 4$ doses. Haemoglobin level of mothers was binary coded based on WHO recommendation [26] as noanaemia $(\geq 11 \mathrm{~g} / \mathrm{dl})$ and anaemia $(<11 \mathrm{~g} / \mathrm{dl})$. Blood group was categorised based on the $\mathrm{ABO}$ system as $\mathrm{A}, \mathrm{B}, \mathrm{AB}$, and $\mathrm{O}$.

\section{Statistical analysis and data management}

Data capture sheets were checked for completeness and accuracy. Data were then coded, entered into Microsoft Excel spreadsheet, and imported into STATA Version 14.0 (College Station, Texas, USA) for cleaning and analysis. Frequencies, percentages, means, or standard deviations were used to describe maternal sociodemographic and obstetric characteristics. Univariate logistic regression models were fitted to estimate the effect of maternal socio-demographic characteristics and maternal obstetric factors (independent variables) on LBW (dependent variable). Parameters that were significant $(<$ 0.05 ) at the univariate level were included in the final multivariable logistic regression models to determine the independent predictors of LBW. Variables were retained in the final model if they were still significant $(<0.05)$ after adjustment. Statistical significance for all the statistical test was considered at $<0.05$.

\section{Results}

\section{Maternal socio-demographic characteristics}

Table 1 presents the socio-demographic characteristics of mothers who delivered at the Sunyani Municipal

Table 1 Socio-demographic characteristics of women delivering at Sunyani Municipal hospital between January 1 and December 31, $2017(N=931)$

\begin{tabular}{lll}
\hline Characteristics & Number & Percent \\
\hline Age of mother & 78 & \\
$<20$ & 618 & 6.38 \\
$20-30$ & 235 & 25.24 \\
$>30$ & $27.21(5.50)$ & \\
Mean (SD) & & \\
Education & 107 & 11.49 \\
No formal education & 451 & 48.44 \\
Basic education & 373 & 40.06 \\
Secondary or higher education & & \\
Occupation & 161 & 17.29 \\
Employed (Government and private) & 530 & 56.93 \\
Self-employed & 147 & 15.79 \\
Unemployed & 93 & 9.99 \\
Student & & 58.75 \\
Residence & 547 & 41.25 \\
Rural & 384 & \\
Urban & & \\
\hline
\end{tabular}

Hospital between January 1 and December 31, 2017. Maternal mean age at delivery was $27.21(\mathrm{SD}=5.50)$ years. Six hundred and eight (66.4\%) mothers were between ages 20 to 30 years. Teenage mothers were only seventy-eight (8.4\%). Basic education (Primary/Junior High School) was the highest level of education attended or completed by most of the mothers (48.4\%) and mothers with no formal education were one hundred and seven (11.5\%). More than half $(56.9 \%)$ of the mothers were selfemployed. Mothers who were employed in the formal sector were one hundred and sixty-one (17.3\%) while unemployed mothers were one hundred and forty-seven (15.8\%). Most (58.8\%) of the women were from rural communities within the study area.

\section{Maternal obstetric characteristics}

As shown in Table 2, the mean gestational age at birth was $37.95(\mathrm{SD}=1.85)$ weeks. Most of the women $(n=$ 797; 85.6\%) gave birth between 37 and 42 weeks gestation. Preterm birth was prevalent in one hundred and thirty-four (14.4\%) mothers. The majority of the women (75.4\%) were para $1-3 ; 15.4 \%(n=143)$ were primiparous. Nearly three-quarters $(73.4 \%)$ of the women had had 2 to 4 pregnancies and $84.9 \%$ of the women had more than four ANC visits during pregnancy. Most (71.9\%) of the mothers received 1 to 3 doses of Intermittent Preventive Treatment with sulfadoxine-pyrimethamine (IPTp-SP) during pregnancy to prevent malaria. Less than half $(40.1 \%)$ of the women were anaemic and blood group $\mathrm{AB}(41.6 \%)$ was the most common blood group among the mothers. The mean birth weight was $2.89(\mathrm{SD}=0.43) \mathrm{kg}$. The majority of the children born within the study period had normal birth weight $(n=842,90.4 \%)$. Only $89(9.6 \%)$ children born within the study period had LBW.

\section{Socio-demographic determinants of LBW}

The association between birth weight and age of mother, education, occupation, and residence of mothers is shown in Table 3. The residence status of mothers and their educational level were the only variables significant in the unadjusted model. After adjusting for the residence of mothers, secondary or higher education remained a significant $(p=0.008)$ predictor of birth weight and mothers who attained this level of education were 63\% (95\% CI $0.20-0.78$ ) less likely to have LBW infants. As shown in Table 3, the odds of delivering a LBW baby in the adjusted (OR 1.77, 95\% CI 1.14-2.76) logistic regression model was significantly high among urban dwellers.

\section{Obstetric determinants of LBW}

Table 4 presents logistic regression models of the association between birth weight and maternal obstetric factors. As shown in the unadjusted model, the odds of LBW significantly decreased with every one-week 
Table 2 Obstetric characteristics of women delivering at Sunyani Municipal hospital between January 1 and December 31, $2017(N=931)$

\begin{tabular}{|c|c|c|}
\hline Characteristics & Number & Percent \\
\hline \multicolumn{3}{|l|}{ Gestational age (weeks) } \\
\hline 26-36 weeks & 134 & 14.39 \\
\hline 37-42 weeks & 797 & 85.61 \\
\hline Mean (SD) & $37.95(1.85)$ & \\
\hline \multicolumn{3}{|l|}{ Parity } \\
\hline First-time mother & 143 & 15.36 \\
\hline 1-3 previous deliveries & 702 & 75.40 \\
\hline$\geq 4$ previous deliveries & 86 & 9.24 \\
\hline \multicolumn{3}{|l|}{ Gravida } \\
\hline Primigravida & 144 & 15.47 \\
\hline Gravida 2-4 & 683 & 73.36 \\
\hline Gravida 5 or more & 104 & 11.17 \\
\hline \multicolumn{3}{|l|}{ Number ANC visits } \\
\hline$\leq 4$ visits & 140 & 15.04 \\
\hline$>4$ visits & 791 & 84.96 \\
\hline \multicolumn{3}{|l|}{ Number of SP doses } \\
\hline None & 22 & 2.36 \\
\hline $1-3$ doses & 669 & 71.86 \\
\hline$\geq 4$ doses & 240 & 25.78 \\
\hline \multicolumn{3}{|l|}{ Haemoglobin } \\
\hline No-anaemia & 558 & 59.94 \\
\hline Anaemia & 373 & 40.06 \\
\hline \multicolumn{3}{|l|}{ Blood group } \\
\hline A & 253 & 27.18 \\
\hline$B$ & 247 & 26.53 \\
\hline$A B$ & 387 & 41.57 \\
\hline $\mathrm{O}$ & 44 & 4.73 \\
\hline \multicolumn{3}{|l|}{ Birth weight of child } \\
\hline$\geq 2.5 \mathrm{~kg}$ (Normal birth weight) & 842 & 90.44 \\
\hline$<2.5 \mathrm{~kg}(\mathrm{LBW})$ & 89 & 9.56 \\
\hline Mean (SD) & $2.89(0.43)$ & \\
\hline
\end{tabular}

increase in gestational age (OR 0.65, 95\% CI 0.570.73 ) and significantly increase with increasing parity (OR 1.42, 95\% CI 1.21-1.66). The odds of LBW decreased with every additional ANC visit (OR 0.71, 95\% CI 0.62-0.80), IPTp-SP dose (OR 0.75, 95\% CI 0.61-0.93) and a gram of haemoglobin (OR 0.73, 95\% CI 0.61-0.89). After adjusting for the effect of other significant covariates, gestational age (OR 0.67 95\% CI $0.59-0.76$ ), parity (OR $1.4395 \%$ CI $1.21-170$ ), number of ANC visits (OR 0.78 95\% CI 0.67-0.90), and maternal haemoglobin level (OR 0.78 95\% CI $0.63-$ $0.95)$ remained significant predictors of LBW.

\section{Discussions}

We found that nearly $10 \%$ of the infants born within the study period had birth weights below $2.5 \mathrm{~kg}$ (LBW). Further analysis revealed that the odds LBW were higher among babies born to teenage mothers (age less than 20 years) and low among babies of mothers older than 30 years albeit not significant, which agrees well with several other studies [23, 27-33] including findings of the 2010 Ghana Demographic and Health Survey [4]. This may be due to poor socioeconomic status, maternal malnutrition, and inadequate antenatal care of teenage mothers as these factors have been reported to influence birth weight of babies born to teenage mothers in lowand-middle-income countries [34-36]. Additionally, biological immaturity and other behavioural factors may have aggravated the increased risk of LBW among teenage mothers. A cohort study in five low-and-middle-income countries found that babies born to teenage mothers have a double risk of LBW [27], which further supports the finding of the current study. Despite the strong evidence supporting the effect of young maternal age on LBW, there are some other studies that did not find any relationship between maternal age and LBW [37, 38].

Mothers who attended or completed basic education and secondary or higher education were less likely to give birth to a low weight baby when compared with those with no formal schooling. Indeed, after adjusting for the residence of mothers, secondary or higher education remained a significant predictor of birth weight and mothers who attained this level of education were $63 \%$ less likely to have LBW infants. This finding is congruent with several studies which link LBW to the educational level of mothers [10, 31, 39]. A possible explanation for this might be that increased years of maternal education brings about improvement in ANC attendance, nutritional status, health-seeking behaviour and enhanced maternal experiences relative to pregnancy and childcare. Furthermore, increased years of maternal education may cause delay in sexual initiation or increase uptake of contraception to prevent pregnancy $[40,41]$. This inadvertently could increase maternal age at first birth and decrease the likelihood of LBW associated with teenage pregnancy.

In this study, the likelihood of delivering a LBW baby was significantly high among urban dwellers, which is consistent with studies in Ethiopia [42] and Bangladesh [24]. It seems possible that these results may be due to urban women attitude toward antenatal care, interpregnancy interval, and iron and vitamin supplementation during pregnancy [24]. For instance, in Zambia, Banda et al. found that urban women did not believe that early commencement of ANC offers any benefits, they had inadequate knowledge about ANC, and negative cultural 
Table 3 Association between socio-demographic characteristics of women delivering at Sunyani Municipal hospital between January 1 and December 31, 2017 and LBW (N=931)

\begin{tabular}{|c|c|c|c|c|}
\hline \multirow[t]{2}{*}{ Characteristics } & \multicolumn{2}{|c|}{ Unadjusted model } & \multicolumn{2}{|l|}{ Adjusted model $^{a}$} \\
\hline & OR $(95 \% \mathrm{Cl})$ & $P$ value & OR $(95 \% \mathrm{Cl})$ & $P$ value \\
\hline \multicolumn{5}{|l|}{ Age of mother (years) } \\
\hline$<20$ & $1.39(0.68,2.85)$ & 0.364 & & \\
\hline $20-30$ & Ref & & & \\
\hline$>30$ & $0.88(0.51,1.49)$ & 0.641 & & \\
\hline \multicolumn{5}{|l|}{ Education } \\
\hline No formal education & Ref & & Ref & \\
\hline Basic education & $0.70(0.38,1.30)$ & 0.267 & $0.73(0.39,1.34)$ & 0.315 \\
\hline Secondary and higher education & $0.37(0.19,0.73)$ & 0.005 & $0.39(0.20,0.78)$ & 0.008 \\
\hline \multicolumn{5}{|l|}{ Occupation } \\
\hline Employed (Government and private) & Ref & & & \\
\hline Self-employed & $1.10(0.58,2.10)$ & 0.754 & & \\
\hline Unemployed & $1.39(0.64,2.99)$ & 0.401 & & \\
\hline Student & $1.85(0.81,4.18)$ & 0.139 & & \\
\hline \multicolumn{5}{|l|}{ Residence } \\
\hline Rural & Ref & & Ref & \\
\hline Urban & $1.85(1.19,2.87)$ & 0.006 & $1.77(1.14,2.76)$ & 0.011 \\
\hline
\end{tabular}

beliefs about early ANC attendance [43]. Given the relevance of early ANC attendance to maternal and neonatal health, these negative attitudes may account for the increased odds of LBW among urban women [44]. However, unlike this study, an earlier study in Ghana reported an increased risk of LBW among women from rural settings [9].

We found that with every one-week increase in gestational age, the odds of LBW significantly decreased. As observed in previous studies, pre-term babies are usually underweight, therefore, once delivery occurs at term the likelihood of a baby weighing above $2.5 \mathrm{~kg}$ is high [10]. Our findings further suggest that the odds of LBW significantly increase with increasing parity, which is in line with the findings of several authors $[9,15,27]$. Up-todate there is no clear mechanism on how parity influences LBW $[45,46]$. However, studies have shown that the increased occurrence of preeclampsia and the younger age of nulliparous women, the incidence of chronic anaemia, diabetes mellitus, and hypertension in

Table 4 Association between obstetric characteristics of women delivering at Sunyani Municipal hospital between January 1 and December 31, 2017 and LBW $(N=931)$

\begin{tabular}{|c|c|c|c|c|}
\hline \multirow[t]{2}{*}{ Characteristics } & \multicolumn{2}{|c|}{ Unadjusted model } & \multicolumn{2}{|l|}{ Adjusted model ${ }^{a}$} \\
\hline & OR $(95 \% \mathrm{Cl})$ & $P$ value & OR $(95 \% \mathrm{Cl})$ & $P$ value \\
\hline Gestational age (weeks) & $0.65(0.57,0.73)$ & $<0.001$ & $0.67(0.59,0.76)$ & $<0.001$ \\
\hline Parity & $1.42(1.21,1.66)$ & $<0.001$ & $1.43(1.21,1.70)$ & $<0.001$ \\
\hline Gravida & $0.86(0.72,1.02)$ & 0.092 & & \\
\hline Number ANC visits & $0.71(0.62,0.80)$ & $<0.001$ & $0.78(0.67,0.90)$ & 0.001 \\
\hline Number of IPTp-SP doses & $0.75(0.61,0.93)$ & 0.011 & & \\
\hline Haemoglobin & $0.73(0.61,0.89)$ & 0.002 & $0.78(0.63,0.95)$ & 0.016 \\
\hline \multicolumn{5}{|l|}{ Blood group } \\
\hline A & Ref & & & \\
\hline B & $0.71(0.39,1.29)$ & 0.272 & & \\
\hline$A B$ & $0.74(0.44,1.25)$ & 0.268 & & \\
\hline $\mathrm{O}$ & $0.99(0.36,2.71)$ & 0.985 & & \\
\hline
\end{tabular}

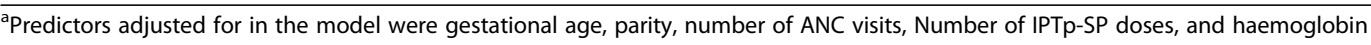


multipara women, and the higher incidence of placenta previa, abruption, abnormal presentation, and haemorrhagic in grand multiparous women may reduce foetal growth and duration of pregnancy, which may predispose to LBW [45, 46].

Another significant finding from this study was that the probability of a woman delivering a LBW baby decreased with every additional ANC visit, IPTp-SP dose and a gram of haemoglobin. The significance of ANC in maternal and child health cannot be overemphasised. There is strong evidence to suggest that quality ANC during pregnancy is important for the health of the expectant mother and the developing foetus. This is ensured through essential interventions such as the identification and management of obstetric complications including preeclampsia, tetanus toxoid immunisation, intermittent preventive treatment for malaria during pregnancy (IPTp), and identification and management of infections including HIV, syphilis and other sexually transmitted infections (STIs) at the ANC [47]. However, poor and late ANC attendance is usually associated with increased odds of LBW [8]. A case-control study collaborated by WHO in Pakistan revealed that delivering a LBW baby decreased with an increase in maternal haemoglobin and that the odds were greater among mothers not using iron supplements during pregnancy [22]. Therefore, mothers of LBW babies had lower haemoglobin levels before delivery. This study agrees with our finding that an increase in haemoglobin reduces the likelihood of LBW.

The most important limitation of the current study lies in the fact that the data used for the analyses were primarily collected for routine healthcare services and not for research purposes or for a specific intervention. Errors may have occurred during the documentation of the records. Notwithstanding this limitation, routine collection of health data may allow for the monitoring and evaluation of public health interventions. Finally, the study analysed data from one hospital and findings may not be generalizable to mothers who attended other hospitals and those who delivered at home.

\section{Conclusion}

The evidence from this study suggests that maternal educational level, residence, haemoglobin level, parity, number of ANC visits, and gestational age are independent predictors of LBW. These findings contribute to the growing literature on the influence of maternal socio-demographic and obstetric factors on LBW in resource-constrained settings. This could guide the development of clinical and public health interventions aimed at reducing LBW and its associated complications.

\section{Abbreviations}

ANC: Antenatal Care; IPTO-SP: Intermittent Preventive Treatment in pregnancy with sulfadoxine-pyrimethamine; JHS: Junior High School; LBW: Low Birth Weight; WHO: World Health Organisation

\section{Acknowledgements}

The authors would like to thank the management and staff of the Sunyani Municipal hospital for their cooperation during the study.

\section{Authors' contributions}

SM and IR designed the study, wrote the protocol, performed the statistical analysis and interpretation, and wrote the first draft of the manuscript. IB and WPW managed the literature search and discussion of the findings. All authors read and approved the final manuscript.

\section{Funding}

No funding was received for this study.

\section{Availability of data and materials}

The datasets used and/or analysed during the current study are available from the corresponding author on reasonable request.

\section{Ethics approval and consent to participate}

The medical superintendent of Sunyani Municipal Hospital, the director of nursing services, and the manager of the maternity unit granted approval and permission for the authors to use the healthcare records of the maternity unit of the hospital for this study. We did not capture identifying information from the records and the confidentiality of the information extracted from the records was ensured in accordance with the data protection act.

\section{Consent for publication}

Not applicable

\section{Competing interests}

The authors declare that they have no competing interests.

\section{Author details}

${ }^{1}$ Department of Nursing, College of Nursing and Midwifery, P. O. Box 10 Nalerigu, Ghana. ${ }^{2}$ Emergency Unit, Sunyani Municipal Hospital, Sunyani, Ghana. ${ }^{3}$ Department of Nursing, Nursing and Midwifery Training College, Gushegu, Ghana.

Received: 21 January 2019 Accepted: 21 May 2019

Published online: 29 May 2019

\section{References}

1. World Health Organization. Essential newborn care and breastfeeding: training modules [Internet]. Copenhagen; 2002. Available from: apps.who. int/iris/bitstream/handle/10665/107481/e79227.pdf?sequence=1 ...y.

2. UNICEF and WHO. Low Birthweight: Country, regional and global estimates contents. NewYork, USA; 2004.

3. Perinatal Education Programme. Newborn Care: Managing normal and high-risk infants in the newborn nursery. South Africa: Perinatal Education Programme; 2009. 1-452 p.

4. Ghana Statistical Service (GSS) Ghana Health Service (GHS) and ICF International. Ghana Demographic and Health Survey 2014 [Internet]. Rockville, Maryland, USA; 2015. Available from: https://dhsprogram.com/ pubs/pdf/fr307/fr307.pdf. Accessed 25 Aug 2018.

5. Lee ACC, Katz J, Blencowe H, Cousens S, Kozuki N, Vogel JP, et al. National and regional estimates of term and preterm babies born small for gestational age in 138 low-income and middle-income countries in 2010. Lancet Glob Heal. 2013;1(1):e26-36.

6. Darmstadt GL, Lawn JE, Costello A. Advancing the state of the world's newborns. Bull World Health Organ. 2003;81(3):222-3.

7. World Health Organization. Born too soon: the global action report on preterm birth [Internet]. Geneva, Switzerland; 2012. Available from: https:// www.who.int/pmnch/media/news/2012/201204_borntoosoon-report.pdf. Accessed 30 Apr 2019

8. Kramer MS. Determinants of low birth weight: methodological assessment and meta-analysis. Bull World Health Organ. 1987;65(5):663-737. 
9. Abubakari A, Kynast-wolf G, Jahn A. Prevalence of abnormal birth weight and related factors in northern region. Ghana BMC Pregnancy Childbirth. 2015;15(335):1-8 Available from: https://doi.org/10.1186/s12884-015-0790-y.

10. Mannocci A, Vaschetto C, Semyonov L, Poppa G, Massimi A, Rabacchi G, et al. Maternal smoking and socio-demographic characteristics in correlation with low birth weight : a Turin ( piedmont) study kajenje matere in socialno-demografske zna č ilnosti $\vee$ povezavi z nizko porodno težo : torinska ( piemontska ) študija. Sjph; 2014. p. 221-5.

11. Beyazit $F$, Pek E, Güngör $A C ̧$, Gencer $M$, Unsal MA. Effect of maternal $A B O$ blood type on birth weight and preeclampsia. Int J Reprod Contraception, Obstet Gynecol. 2017:6(6):2164-7.

12. Cozzoli E, Neri A, Bottini E, Magrini A. Effect of smoking and ABO blood groups on maternal age at child bearing and on birth weight. Eur J Obstet Gynecol Reprod Biol. 2011;159:83-6.

13. Bhaskar RK, Deo KK, Neupane U, Bhaskar SC, Yadav BK, Pokharel HP, et al. A case control study on risk factors associated with low birth weight babies in eastern Nepal. Int J Pediatr. 2015;2015(Article ID 807373):1-7.

14. Shahnawaz K, Choudhary S, Kumar Gautam S, Das P, Pal R, Kumar L. Association between maternal socio-demographic factors and low birth weight newborn in a rural area of Bihar. India South East Asia J Public Heal. 2015;4(1):30-4

15. Azhar BS, Islam KS, Ferdouse A, Afrin S. Maternal obstetric and morbidity factors in relation to infant birth weight. Sch J Appl Med Sci. 2014;2(2A): 539-47

16. Isiugo-abanihe UC, Oke OA. Maternal and environmental factors influencing infant birth weight in Ibadan. Nigeria African Popul Stud. 2011;25(2):1-17.

17. Jawarkar AK, Lokare PO, Dore S. Original article study of socio-demographic and maternal determinants influencing birth-weight. J Mahatma Gandhi Inst Med Sci. 2012;17(September):28-33.

18. Ghana Statistical Service (GSS). Sunyani municipality [Internet]. Accra, Ghana; 2014. Available from: www.statsghana.gov.gh/docfiles/2010_District_Report/... SunyaniMunicipal.pdf\%0A\%0A

19. Afable- BA, Afable-munsuz A. Pregnancy intention and preterm birth: differential associations among a diverse population of women. Perspect Sex Reprod Health. 2008;40(20):29-36.

20. Yilgwan CS, Utoo TB, Hyacinth HI. Maternal characteristics influencing birth weight and infant weight gain in the first 6 weeks post - partum : a cross sectional study of a post - natal clinic population. Niger Med J. 2012:53(4): 200-5.

21. Nketiah-amponsah E, Abuosi A Maternal Socio-Economic Status and Childhood Birth Weight: A Health Survey in Ghana Maternal SocioEconomic Status and Childhood Birth Weight: A Health Survey in Ghana 2012;(March 2014).

22. Rizvi SA, Hatcher J, Jehan I, Qureshi R. Maternal risk factors associated with low birth weight in Karachi: a case-control study. East Mediterr Heal J. 2007; 13(6):1343-52.

23. Bugssa G, Dimtsu B, Alemayehu M. Socio demographic and maternal determinants of low birth weight at Mekelle hospital, northern Ethiopia : a cross sectional study. Am J Adv Drug Deliv. 2014:2(5):609-18.

24. Azimul S, Matin A, Shabnam J, Shamianaz S, Baneerje M. Maternal factors affecting low birth weight in urban area of Bangladesh. J Dhaka Med Coll. 2009;18(1):64-9.

25. World Health Organization. Preterm birth [Internet]. 2018 [cited 2019 Apr 22]. Available from: https://www.who.int/news-room/fact-sheets/detail/preterm-birth

26. World Health Organization. Haemoglobin concentrations for the diagnosis of anaemia and assessment of severity. Vitamin and mineral nutrition information system. Geneva; 2011. Available from: http://www.who.int/ vmnis/indicators/haemoglobin.pdf. Accessed 30 Apr 2018.

27. Fall CHD, Sachdev HS, Osmond C, Restrepo-mendez MC, Victora C, Martorell $R$, et al. Association between maternal age at childbirth and child and adult outcomes in the off spring : a prospective study in fi ve low-income and middle-income countries ( COHORTS collaboration ). Lancet Glob Heal. 2015;3(7):e366-77

28. Li $Y$, Chang T. M aternal $d$ emographic and $p$ sychosocial $f$ actors a ssociated with I ow b irth w eight in eastern Taiwan. Kaohsiung J Med Sci. 2005;21(11):502-10.

29. Restrepo-méndez MC, Lawlor DA, Horta BL, Matijasevich A, Santos IS, Menezes AMB, et al. The Association of Maternal age with birthweight and gestational age: a cross-cohort comparison. 2015;29:31-40.

30. Aras RY. Is maternal age risk factor for low birth weight? Arch Med Heal Sci. 2013;1(1):33-7.
31. Amosu AM, Degun AM, Ter GD. Maternal socio-demographic characteristics as correlates of newborn birth weight in urban Abeokuta. Nigeria Biomed Res. 2014;25(4):612-6.

32. Manyeh AK, Kukula V, Odonkor G, Ekey RA, Adjei A, Narh-bana S, et al. Socioeconomic and demographic determinants of birth weight in southern rural Ghana : evidence from Dodowa health and demographic surveillance system. BMC Pregnancy Childbirth. 2016;16(160):1-9.

33. Afeke I, Mac-ankrah L, Jamfaru I, Amegan-aho KH, Mbroh HK, Lokpo SY, et al. Maternal age, low birth weight and early neonatal death in tertiary Hospital in the Volta Region of Ghana. J Pediatr. 2017;7:254-62.

34. Johnson W, Moore SE. Adolescent pregnancy, nutrition, and health outcomes in low- and middle-income countries : what we know and what we don ' t know. Int J Obstet Gynaecol. 2016;123:1589-92.

35. Govender T, Reddy P, Ghuman S. Obstetric outcomes and antenatal access among adolescent pregnancies in KwaZulu-Natal, South Africa obstetric outcomes and antenatal access among adolescent pregnancies in KwaZuluNatal , South Africa. South African Fam Pract [Internet]. 2017;6190(August): 1-7 Available from: https://doi.org/10.1080/20786190.2017.1333783.

36. Castro R, Fajnzylber E. Income inequality and adolescent fertility in lowincome countries. Cad Saúde Pública. 2017;33(9):1-8.

37. Rana SS. Effect of maternal age on fetal weight. Med J Shree Birendra Hosp. 2011:10(December):15-7.

38. Patel PB, Bavarva NR, Patel MJ. Sociodemographic and obstetrical factors associated with low birth weight : community based retrospective study in an urban slum of Western. Appl Med Res. 2015;1(3):94-8.

39. Tampah-naah AM, Yendaw E, Tampah-naah AM, Anzagra L, Yendaw E. Factors correlate with low birth weight in factors correlated with low birth weight in Ghana. Br J Med Med Res. 2016;4(16):1-8.

40. Mohammed S, Abdulai A, Iddrisu OA. Pre-service knowledge, perception, and use of emergency contraception among future healthcare providers in northern Ghana. Contracept Reprod Med. 2019;4(1):1-7.

41. Yakubu I, Salisu WJ. Determinants of adolescent pregnancy in sub-Saharan Africa : a systematic review. Reprod Health. 2018;15(1):15.

42. Tema T. Prevalence and determinants of low birth weight in Jimma zone, Southwest Ethiopia. East Afr Med J. 2006;83(7):366-71.

43. Banda I, Michelo C, Hazemba A. Factors associated with late antenatal care attendance in selected rural and urban communities of the Copperbelt Province of Zambia. Med J Zambia. 2012;39(3):29-36.

44. Regina C, Wany M, Strufaldi L, De CLR, Puccini RF. Adequacy of antenatal care and its relationship with low birth weight in Botucatu, São Paulo , Brazil : a case-control study. BMC Pregnancy Childbirth [Internet]. 2014; 14(225) Available from: http://www.biomedcentral.com/1471-2393/14/255. Accessed 30 Apr 2019

45. Aliyu MH, Jolly PE, Ehiri JE, Salihu HM. High parity and adverse birth outcomes : exploring the maze. BIRTH. 2005;32(1):45-59.

46. Shah PS. Parity and low birth weight and preterm birth : a systematic review and. Acta Obstet Gynecol. 2010;89:862-75.

47. Lincetto O, Mothebesoane-Anoh S, Gomez P, Munjanja S. Antenatal Care. In: Lawn J, Kerber K, editors. Opportunities for Africa 's newborns: practical data, policy and programmatic support for newborn care in Africa. Cape Town: World Health Organization; 2006. p. 51-62. Available from: www.who. int/pmnch/media/publications/africanewborns/en/.

\section{Publisher's Note}

Springer Nature remains neutral with regard to jurisdictional claims in published maps and institutional affiliations.

Ready to submit your research? Choose BMC and benefit from:

- fast, convenient online submission

- thorough peer review by experienced researchers in your field

- rapid publication on acceptance

- support for research data, including large and complex data types

- gold Open Access which fosters wider collaboration and increased citations

- maximum visibility for your research: over $100 \mathrm{M}$ website views per year

At BMC, research is always in progress.

Learn more biomedcentral.com/submissions 